\title{
Funds and Policies: Analysis of the Changes in the Structure of Chinese TV Drama Industry in the Past Six Years
}

\author{
Yuqiao Yan, Tianzi Li* \\ ${ }^{1}$ Graduate student of drama and film and television science, School of Arts and Media, Beijing Normal \\ University \\ ${ }^{2}$ Digital media art, School of Arts and media, Beijing Normal University \\ *Corresponding author email: 1115319341@qq.com
}

Keywords: TV drama industry; capital chain; channel vendor; bubble; advertiser; policy

\begin{abstract}
The Chinese TV drama industry is one of the focuses of Chinese cultural industry in recent years. The status of TV drama industry can be observed by observing the development of TV drama procurement in the past six years. By observing the phenomenon of capital bubble and capital winter in the TV drama industry in recent years, this paper intends to analyze the changes in the TV drama industry structure from the perspective of capital policy, and propose relevant suggestions for the future development of Chinese TV drama industry.
\end{abstract}

\section{Introduction}

Chinese TV drama industry chain, procurement system and development context. The TV drama industry is one of the key points of China's efforts in the cultural industry in recent years. At the beginning of this century, when Chinese TV stations generally practice separation of production and broadcasting, the broadcast channels and producers are divided into different links in the industrial chain. In addition to homemade dramas, mainstream video sites have also adopted a buying strategy to introduce TV dramas. From the procurement quantity, price and investment/return ratio, etc., we can see the development of China's TV drama industry. Therefore, this paper chooses iQiyi and China Beijing TV Station as the representative blueprint of network medias and TV medias.

In the most popular marketing mode of TV drama-the "procurement-broadcasting" mode, industrial chain is mainly the mode of "producer-integrator-channel-advertiser". Producers are the film and television production companies that include production factors such as directors, actors, screenwriters, and video cameras. They are responsible for providing filming solutions and complete TV dramas. Integrators are similar to intensive package sellers of cable TV, and they are gradually being replaced; channel vendors, including TV stations, video sites and other terminals, are responsible for purchasing existing TV drama products and bringing them into the platform, and obtaining audience information and ratings/CTR through play back; and the advertiser serves ads to the channel vendors based on the audience of channel. It is generally believed that the producer is a front-end industry and the channel vendor is a back-end industry. Overall, the Chinese TV drama industry in 2012-2018 experienced a period from overheating to depression. This process is caused by factors such as funds, policies, and substitutions. In terms of capital, due to the large-scale entry of capital into the industry, the rules of front-end game changed, which led to the formation of bubble in the cycle of the TV industry capital in the past six years and the bursting of market; the new requirements of policy have made the sales procurement model and quantity have fundamental changes; and the dominant voice has also transformed from TV stations to video sites for channels.

\section{The rise and fall of capital bubble: the rise and decline of overcapacity}

From the perspective of capital in Chinese TV drama industry, the main turning point was completed around 2013-2014. In 2014, a large amount of hot money poured in, and capital began to be optimistic about such well-known film and television production front-end enterprises such as 
Huace Film and Television, Hualu Baina, etc., and major capital investment banks began to invest in film and television production, which first formed ample funds for film and television production companies, and began to reform the big production. In the case of Huace Film and Television, in 2014, the total value of the company in the previous two years was 30 times higher than that before the company was just listed. It should be noted that the right to broadcast at this time is still in the hands of channel dealers represented by TV stations. In order to better withdraw funds, the capital side put pressure on the production company, so that the producers will spend a lot of money to hire more big-name stars, use more sophisticated audio-visual recording technology, use more powerful director and scriptwriting team, and even expand the yield of TV drama products. At this time, there is a shortage of supply in the front-end film and television human resources market. Excessive demand leads to an increase in the price of human resources. This change is centered on the changes in the pay of actors/directors/screenwriters. Before the release of the Chinese government's "limitation of actor remuneration" in 2018, the domestic first-line TV drama actors' remuneration was getting higher and higher, reaching a maximum of 160 million Yuan per episode, and even 200 million Yuan per episode. In addition to the increase in the price of human resources, the expansion of funds also result in another consequence that is the large-scale expansion of production capacity. By 2015, the total output value of Chinese TV dramas has reached 50 billion Yuan, and more of the produced TV dramas have not been purchased or broadcast. In 2016, the total number of TV dramas produced by TV drama production companies nationwide was 15,000 episodes, and only 6,000 episodes were purchased and broadcast by TV drama/Internet platforms, which means that more than half of the produced TV series did not enter the back-end industry chain. From this point of view, this is not a capacity expansion in the traditional sense. Only the expansion of the upstream without the imbalance of downstream demand can only lead to greater structural imbalance. At the same time, the policy of broadcast for Chinese TV stations at this time is called "one drama and four stars", that is, each TV drama can be broadcast simultaneously by four satellite TV stations, which has caused the hot drama to be pushed up, and a large number of products have been idle. Therefore, although this kind of capital-led prosperity has greatly improved the level of audio-visual production of Chinese TV dramas, it can only be called overcapacity in terms of the production structure in which products are obviously oversupply.

The status quo of a large number of idle products in 2015 has attracted the attention of government agencies. Under the government-led economic system, when the economy has a structural problem, the first reaction of government is to carry out macroeconomic regulation and control through administrative orders. In order to digest excess capacity, the Chinese government cancelled the "one drama and four stars" policy, but changed it to the "one drama and two stars" policy. The purpose of this policy is to reduce the situation in which the same TV drama product occupies too much channel resources by restricting each drama can be only broadcast by two satellite TV stations. It can be mandatory to make the TV stations that do not have the right to broadcast popular TV dramas, in turn, will play more TV drama products that have not yet been broadcasted, in order to digest the 9000 episodes of TV drama stocks from 2014 to 2015 by using the means of allocating demand to achieve the purpose of cleaning up inventory and reducing supply and demand differences. However, the government department ignores the market fact of audience ratings, that is, the higher the TV dramas, the more the advertisers are willing to pay. Under this kind of market policy, the restrictions of two TV stations make the channel dealers scramble for popular TV dramas. In order to grab the hot products, the purchase price of each episode is getting higher and higher, which leads the producers to raise the price without fear. In 2015, the averaged purchase price of popular TV dramas is about 3 million Yuan per episode. In 2018, the purchase price of the popular big drama "Ruyi Biography" has reached 10 million Yuan per episode. In this way, the popular dramas are taken over in the back end because their demand exceeds the supply, and there is sufficient funds at the front end. The bargaining power of the producers is getting stronger and stronger. The phenomenon of "TV dramas open plunder" comes here, and the two-star policy is counterproductive. After the popular episodes have been run out, the channel dealers will not buy the unpopular episodes for the purpose of profit. Instead, they choose 
to "book" the popular episodes of the future, which has led to the magical phenomenon of Chinese TV drama industry: TV drama "Futures". The TV "Futures" is a channel vendor's investment with the nature of venture capital. Take the TV drama "Stories in surgical department" purchased by Beijing TV station as an example, when the film was approved for initiation in 2016, Beijing TV Station and Shanghai TV Station began to reserve the right to broadcast the film in a price comparison manner. The rules of game in this seller's market are as follows: In the hands of Beijing $\mathrm{TV}$, there was no complete script at all. They could only see the outline of the script, the starring stars included Jin Dong, Bai Baihe, and the list of directors. The film purchasing director needed to speculate on the completion of the drama, the expected audience ratings, the source of advertisements, and the expected rate of return based on the only information available, and purchased the rights to broadcast this unplayed TV drama based on these speculations. As the vice president of iQiyi said, "In the first two years, the purchases of TV drama were all gamblers' venture capital.” This kind of risk-free gambling has caused the producers to be more fearless and pricey.

Finally, in 2018, the bubble of capital broke down and the capital winter began to fall. The sign of this change is that the back end of industry chain is overwhelmed by the weight and begins to lose money. According to the statistics of survey institutions in 2018, all broadcast platforms including the Internet platform are losing money in 2018. Tencent lost 10 billion Yuan in the whole year, Youku lost 4.2 billion in the first half of the year, and iQiyi lost 5 billion in the first half of the year. The TV stations are also losing except three channels CCTV, Hunan and Zhejiang. The reason of loss is obvious. The channel vendors have incurred a lot of expenses in order to purchase the episodes in the producer-led seller market. The front-end expansion of the entire industry chain is borne by the back-end, and the advertisers cannot pay the corresponding advertising costs, so the deficit of channel vendors are reflected. The direct consequence is that the channel dealers reduce the number of ordering episodes, and the large number of episodes previously produced by the manufacturer can only be hoarded in their own hands and cannot be realized. In this environment, the capital from the producers began to withdraw from the market. The producers had nothing but a large number of products that could not be sold. Therefore, in 2018, the Chinese TV drama industry became the beginning of the "bubble burst". In order to cope with the winter of losses, various video websites began to turn from vicious competition to cooperation. The purchased drama of TV stations also shifted from bidding strategy to mutual notification, aiming to curb the phenomenon of high price at the front end.

\section{The regulation of policy: from advertising to price}

The Chinese government has always played an important role in the production and marketing of film and television industry. Under the government's Keynesian intervention economic policy, the government can directly impose rigid requirements on all aspects of the industrial chain. Therefore, when there is a problem in the TV drama industry, the government will respond accordingly to regulate the market failure. And these policies have achieved corresponding results for the industrial chain, and some are just the opposite.

The first is the 2012 "Advertising Order." The details of this order are: It is forbidden for TV stations to insert advertisements during the broadcasting episodes of TV drama. The main reason for canceling the intermediate advertisements is mainly due to the criticism of the public opinion for TV stations. Prior to this, in order to strive for better advertising efficiency, TV stations will insert 1-2 advertisements in the hot drama of hot-spot period, which makes the episodes of about 50 minutes be cut into 2-3 segments, which seriously affects the audience's viewing effect. This advertising restriction has caused the TV drama profit margin of Beijing TV to drop directly from the original $100 \%$ to $60 \%$.

"One drama and two stars" policy in 2015 is also mentioned above. The purpose of this policy was actually to digest excess capacity, but because there was no corresponding control measures for the front end, it had the opposite effect. Advertising was decreasing and TV purchase prices were rising. After that, the script could not be seen in purchasing TV drama "Futures", and the film 
director could only "compete" in the stars through the actors. The price of the actor was also lifted up, and there was a phenomenon in which the actors had more endorsements and their dramas were bought more.

By 2018, when the industry winter came, the government finally realized the consequences of the front-end expansion on the industrial chain. Therefore, the National Radio and Television Administration has issued the most stringent order to limit the price of the front end. For example, the remuneration for an actor should be less than 1 million Yuan/episode; TV drama purchase price cannot exceed 9 million Yuan/episode. Once this strictly restricted order was issued, it's resisted by the producers. However, in the long run, the consequences of front-end expansion of producers do need to be governed, but this approach is more stringent. It remains to be seen what the final governance effect will be.

\section{Enlightenment from changes in industrial structure}

According to the changes in the industrial structure in the past six years, we can get the following enlightenment on the TV drama industry:

Firstly, rational financing, rational planning of production capacity. From the perspective of overcapacity caused by the blind expansion of capital after 2014, only the back-end demand can be solved to achieve a real expansion in the front-end capacity; unilateral expansion will only hurt the industry itself.

Secondly, establish an internal industry standard system. Chinese TV drama industry does not have a similar organization as trade union in Western countries. Therefore, there is no self-discipline system for remuneration and contracts. Therefore, there will be a phenomenon in which the price of actors is always high and the quality of finished dramas cannot be guaranteed. At the same time, in the perspective of channel vendors, establishing a sound communication and dialogue mechanism to avoid vicious competition can enable the industry to develop in a healthy manner.

Thirdly, establish and improve the relevant insurance system. At the moment when purchasing TV dramas "futures" production capacity, channel dealers can hardly control the final effect of TV drama production, and there is no corresponding guarantee system for the film. Therefore, it will take a very big risk for channel dealers. The relevant insurance system has been quite perfect in the film industry, and its related experience is also worth learning for TV drama industry.

\section{References}

[1] Yao Rui, Liu Yang. The Evolution of TV Drama Industry under the Policies and Regulations Since the New Century [J]. Contemporary Film, 2013 (07): 137-141.

[2]Huang Haitao, Wang Yihan. The Dilemma and Outlet of China's TV Drama Industry [J]. Modern Communication (Journal of Communication University of China), 2013, 35(06): 115-117.

[3] Li Chunmei, Jiang Hong. Reconstruction of TV Drama Industry Value Chain in the Era of Digital Media [J]. Journalism, 2008(01): 10-12+18.

[4] Dong Haoyu. Chinese TV Drama Industry: Difficulties and Countermeasures [J]. Journal of Shanghai University (Social Science Edition), 2008 (03): 60-69.

[5] Yang Wenyan. Research on the Development Strategy of TV Drama Industry [J]. China Radio and Television Journal, 2008(06): 26-28+25.

[6] Yu Xiaofeng. Media Ecology and Policy Adjustment in China’s TV Drama Industry [J]. Nanjing Social Sciences, 2014(12): 115-120+149.

[7] Song Peiyi, Liu Dandan. Development Strategy of Chinese TV Drama Industry Based on the Perspective of Profit Model [J]. China TV, 2015(01): 100-103.

[8] Wang Jia. Research on the Development of China's TV Drama Industry under the Background of Media Convergence [J]. Publishing Wide Angle, 2016(14): 74-76. 
[9] Tang Jian, Pan Jin. Analysis of Chinese TV Drama Industry Value Chain [J]. Economic Guide, 2007(05): 56-57.

[10] Zhou Kai. Financing Reconstruction of Domestic TV Drama Industry Chain [J]. Press, 2006(05): 29-30.

[11] Wei Ren, Helen Woodfield. Chinese females' date refusals in reality TV shows: Expressing involvement or independence?[J]. Discourse, Context \&amp; Media, 2016,13.

[12] Jinoh Oh, Sungchul Kim,Jinha Kim,Hwanjo Yu. When to recommend: A new issue on TV show recommendation [J]. Information Sciences, 2014,280. 